\title{
Blocking malaria transmission to Anopheles mosquitoes using artemisinin derivatives and primaquine: a systematic review and meta-analysis
}

Solomon Mequanente Abay

\begin{abstract}
Background: Among the currently used drugs in malaria case management, artemisinin derivatives and primaquine have an impact on the transmissible stages of Plasmodium falciparum. Hence, they reduce the transmission of the parasite from the patient to the mosquitoes. The present study aimed to assess evidence for this hypothesis from controlled trials.

Methods: All controlled clinical trials evaluating the transmission blocking activity of artemisinin derivatives and primaquine with or without other antimalarials were included in this systematic review. PubMed, Google Scholar, Web of Science, ScienceDirect, Medscape and the Cochrane library were systematically searched without language, publication status or date restrictions. The literature references were also scanned manually. The last search was run on July 15, 2013. Search terms included artemisinin derivatives, primaquine, malaria transmission, transmission blocking/reducing drugs and mosquito infection. The outcome measure was the mosquito infectivity rate after treatment of patients. Data were compared using odds ratio $(\mathrm{OR})$, in random effects models.

Results: Nine trials with a total of 13,831 mosquitoes were included in the meta-analysis. After combining the trials, the transmission of $P$. falciparum to Anopheles mosquitoes were lower in artesunate, artemether-lumefantrine and primaquine groups as compared with their control counterparts with OR of 0.36 (95\% confidence interval (Cl), 0.14-0.90), 0.49 ( $95 \% \mathrm{Cl}, 0.31-0.79)$ and 0.09 (95\% Cl, 0.01-0.73); respectively. In non-comparative longitudinal studies, the use of a single-dose of primaquine was shown to deter the transmission of malaria briefly.

Conclusion: Evidence on the transmission blocking effect of artemisinin derivatives and primaquine is conclusive. Trials evaluating the combined impact of artemisinin derivatives and primaquine on malaria transmission is urgently needed.
\end{abstract}

Keywords: Malaria transmission blocking, Artesunate, Artemether-lumefantrine, Primaquine, Systematic review, Meta-analysis

\section{Background}

Globally, an estimated 3.3 billion people were at risk of malaria in 2011, with populations living in sub-Saharan Africa having the highest risk of malaria infection [1]. Between 2000 and 2010, malaria mortality rates fell by $26 \%$ around the world. In the World Health Organization (WHO) African Region the decrease was 33\%. During this period, an estimated 1.1 million malaria deaths were

Correspondence: solomonabay@gmail.com

Department of Pharmacology, School of Medicine, Addis Ababa University, P.O. Box 9086, Addis Ababa, Ethiopia

\section{() Biomed Central}

(c) 2013 Abay; licensee BioMed Central Ltd. This is an Open Access article distributed under the terms of the Creative Commons Attribution License (http://creativecommons.org/licenses/by/2.0), which permits unrestricted use, distribution, and reproduction in any medium, provided the original work is properly cited. averted globally, primarily as a result of a scale-up of interventions with a proven track record [2,3]. However, malaria transmission still occurs in 99 countries around the world, and the malaria burden continues to cripple health systems in many African countries. In 2010, this entirely preventable and treatable disease caused an estimated 655,000 deaths worldwide [4].

Proven strategies for malaria control include early treatment of the illness with artemisinin-based combination therapies (ACTs) [5], intermittent preventive treatment for pregnant women $\left(\mathrm{IPT}_{\mathrm{P}}\right)$ [6], and using measures that 
reduce the risk of infection such as indoor residual spraying (IRS) or insecticide-treated nets (ITNs) [7]. These tools and strategies have shown to be effective at contributing to malaria control [8]. Among the drugs used currently in malaria case management, the ACTs and primaquine have an impact on the transmissible stages of Plasmodium falciparum. It is assumed that artemisinin derivatives act against young gametocytes, whereas primaquine acts on mature gametocytes, which are usually present in the circulation at the time when the patient presents for treatment [9].

Independent reports and a pooled data analysis study speculated about the malaria transmission reduction by artemisinin derivatives from malaria patients to Anopheles gambiae, a major malaria vector in Africa [10]. Similarly, many studies have reflected the impact of primaquine on malaria transmission from patients to Anopheles stephensi, a sub-tropical species that predominates in Asia. However, no systematic analysis has been performed on the transmission blocking activity of artemisinin derivatives and primaquine. The present study attempts to make a systematic review and meta-analysis of the impact of artemisinin derivatives and primaquine on malaria transmission to the vector, and to measure whether there are general trends across the different reports on the change in malaria transmission due to artemisinin derivatives and primaquine. The study also explores the reasons for variations across the reports.

\section{Methods}

\section{Conduct of systematic review and search strategy}

The investigator developed a protocol for this systematic review and conducted it in accordance with the PRISMA (Preferred Reporting Items for Systematic Review and MetaAnalyses) statement (Additional file 1: Checklist S1) [11]. A search was conducted to identify studies assessing malaria transmission blocking effect of drugs. PubMed, Google Scholar, Web of Science, ScienceDirect, Medscape and the Cochrane library were systematically searched without language, publication status or date restrictions. Literature references were also scanned manually. The last search was run on July 15, 2013. Search terms included artemisinin derivatives, primaquine, malaria transmission, transmission blocking/reducing drugs and mosquito infection (Additional file 2: Table S1). Studies comprising cases of P. falciparum treated with antimalarials (artemisinin derivatives and/or primaquine) and evaluating malaria transmission to Anopheles mosquitoes were included. Based on the inclusion criteria, studies for both artemisinin derivative (artesunate and artemether) and primaquine were selected for qualitative and quantitative synthesis. Figure 1 outlines the identification of studies for this systematic review and meta-analysis.

\section{Inclusion and exclusion criteria}

Once it was determined that a paper contained a study on malaria transmission after interventions (artemisinin derivatives or primaquine), the full length article was consulted to check whether studies fulfill the following inclusion criteria for the meta-analysis:

i. controlled clinical trial on malaria patients;

ii. study on malaria transmission test from a patient to mosquito after treating the patient with the existing antimalarials; and

iii. evaluating mosquito mid-gut for oocyst prevalence to measure the extent of malaria transmission.

Similar trials with the aforementioned criteria were also included for the qualitative synthesis. Studies involving laboratory animals or trials without control arms were excluded in the meta-analysis.

\section{Study design and outcome measures}

The endpoints were mosquito infection prevalence out of all mosquitoes getting a blood-meal on patients after treatment with antimalarials. The endpoint evaluation was done in mosquitoes following their blood-meal directly on patients and artificial membrane feeding apparatus in primaquine trials and artemisinin derivatives; respectively. A data extraction sheet was used by the investigator to calculate the prevalence of mosquito infection in each trial. Information was extracted from each included trial on characteristics of trial participants, types of intervention (including type, dose, duration and frequency) and trial outcomes (mosquito infection prevalence). The odds of the end points from mosquitoes in the categories of artemisinin derivatives/primaquine and control (standard drugs) were calculated. The odds ratio (OR) and 95\% confidence intervals $(\mathrm{CI})$ for the prevalence of mosquito infection was then calculated.

The risk of bias in the studies used for meta-analysis was assessed by the investigator in an un-blinded manner using a tool developed by the Cochrane Collaboration (focusing on specific domains including random sequence generation, allocation concealment, blinding of participants and personnel, blinding of outcome assessment, incomplete outcome data, selective reporting) [12]. Due to the small number of studies identified, trials were not excluded based on quality assessment. For the same reason, publication bias was not assessed [12].

\section{Statistical analysis}

Meta-analysis was performed using Meta-analyst, a software for meta-analysis of binary, continuous and diagnostic data [13]. The random effect method was used to test for differences in binary outcomes between artemisinin derivatives/primaquine and control (standard drug).

Heterogeneity, the variations among study outcomes, was checked by $t a u^{2}$ statistic, chi-square based Q-test, $I^{2}$ statistics and heterogeneity P-value. The author chose the 


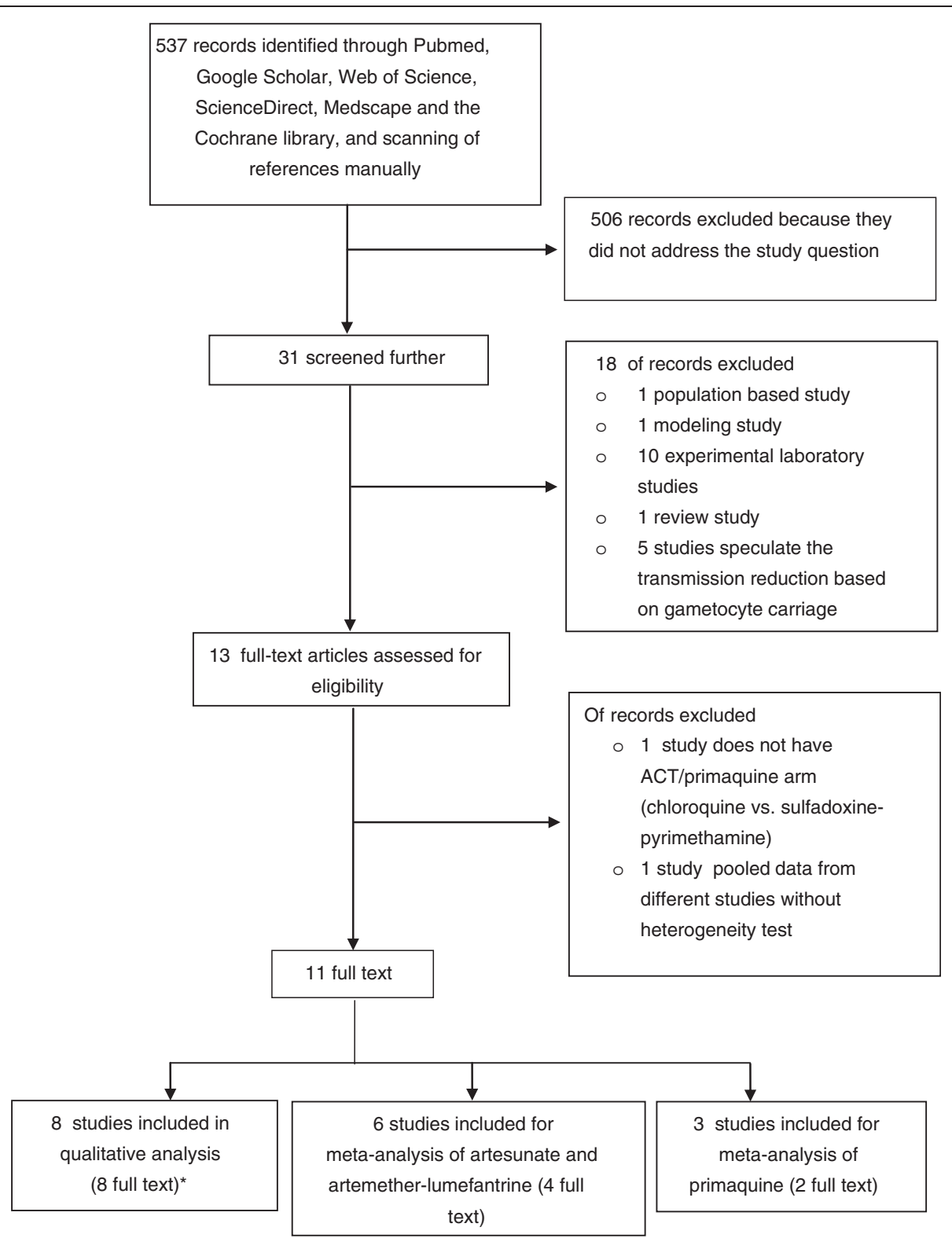

Figure 1 Study selection flow diagram. *three articles were used as sources of data for both qualitative and quantitative synthesis.

random effects meta-analytic model (DerSimonian and Laird) [14] to calculate the combined OR and 95\% CI, even in a meta-analysis with low level of heterogeneity, in order to accommodate the random variation within the studies and the variation between the different studies.

\section{Results}

\section{Description of included studies}

The literature search identified the transmission blocking trials at the level of mosquitoes using two artemisinin derivatives (artesunate and artemether) and primaquine. Of 31 potentially relevant publications, only 6 publications (nine studies) on artemisinin derivatives and primaquine, fulfilled the inclusion criteria for the meta-analysis (Table 1). Eight publications were qualified for the qualitative analysis of transmission blocking property of primaquine and artemisinin derivatives.

Some of the publications, which fulfilled the inclusion criteria, had results of multiple studies; and these were used to generate effect sizes for the transmission blocking property of drugs (artesunate, artemether or primaquine) vs. controls. The studies used in the quantitative analysis were from Africa (Gambia and Kenya) and USA dealing with artemisinin derivatives and primaquine; respectively. 
Table 1 Characteristics of trials included in the meta-analysis

\begin{tabular}{|c|c|c|c|c|c|}
\hline $\begin{array}{l}\text { Location } \\
\text { (Study year) }\end{array}$ & Participants & Treatment arms & $\begin{array}{c}\text { Mosquitoes } \\
\text { (numbers used) }\end{array}$ & $\begin{array}{c}\text { Mosquito } \\
\text { infection method }\end{array}$ & Ref. \\
\hline Gambia* (2000) & Children (1-9 yrs) & Artesunate $[a]+$ chloroquine $[b]$; chloroquine $[b]$ & Anopheles gambiae (1208) & Membrane feeding & [15] \\
\hline Gambia (1999) & Children & $\begin{array}{l}\text { Artesunate }[a]+\text { sulfadoxine-pyrimethamine }[\mathrm{f}] \text {; } \\
\text { sulfadoxine-pyrimethamine }[\mathrm{f}]\end{array}$ & Anopheles gambiae (3192) & Membrane feeding & [16] \\
\hline Gambia (1998) & Children & $\begin{array}{l}\text { Artesuante }[\mathrm{g}]+\text { sulfadoxine-pyrimethamine }[\mathrm{f}] \\
\text { sulfadoxine-pyrimethamine }[\mathrm{f}]\end{array}$ & Anopheles gambiae (2688) & Membrane feeding & [16] \\
\hline Kenya (2003-4) & Children (6 months-10 yrs) & $\begin{array}{l}\text { Sulfadoxine-pyrimethamine }[\mathrm{h}]+\text { placebo }[\mathrm{i}] ; \\
\text { artesunate }[\mathrm{a}]+\text { + sulfadoxine-pyrimethamine }[\mathrm{h}] \\
\text { sulfadoxine-pyrimethamine }[\mathrm{h}]+\text { Amodiaquine }[\mathrm{j}] ; \\
\text { artemether-lumefantrine }[\mathrm{k}]\end{array}$ & Anopheles gambiae (3000) & Membrane feeding & {$[17]$} \\
\hline Gambia (2002) & Children (1-10 yrs) & $\begin{array}{l}\text { Artemether-lumefantrine [c]; chloroquine[d] + } \\
\text { sulfadoxine-pyrimethamine [e] }\end{array}$ & Anopheles gambiae (540) & Membrane feeding & [18] \\
\hline USA $A^{* *}$ & Adults & Primaquine [l]; Sulfadiazine + pyrimethamine [m] & Anopheles stephensi (30) & Direct skin bite & [19] \\
\hline USA*** (1968) & Adults ( 25 to $41 \mathrm{yrs}$ ) & Primaquine [l]; pyrimethamine [n] & Anopheles stephensi (163) & Direct skin bite & {$[20]$} \\
\hline
\end{tabular}

$\mathrm{a}=4 \mathrm{mg} / \mathrm{kg}$ for 3 days.

$\mathrm{b}=25 \mathrm{mg} / \mathrm{kg}$ over 3 days: $10 \mathrm{mg}, 10 \mathrm{mg}, 5 \mathrm{mg}$.

$\mathrm{c}=$ Each dose: One half-tablet of co-artemether ( $20 \mathrm{mg}$ artemether $+120 \mathrm{mg}$ of lumefantrine) per $5 \mathrm{~kg}$ body weight up to $24 \mathrm{~kg}$ (two tablets).

$\mathrm{d}=$ Three daily doses of $10 \mathrm{mg} / \mathrm{kg}$.

$\mathrm{e}=$ One half-tablet of SP (12.5 mg of pyrimethamine with $250 \mathrm{mg}$ of sulfadoxine per half-tablet).

$\mathrm{f}=$ One-half tablet of pyrimethamine-sulfadoxine ( $12.5 \mathrm{mg}$ pyrimethamine $+250 \mathrm{mg}$ sulfadoxine) for a body weight of $10 \mathrm{~kg} \&$ a further one-quarter tablet for each $5 \mathrm{~kg}$ increase.

$\mathrm{g}=4 \mathrm{mg} / \mathrm{kg}$ immediate dose of artesunate.

$\mathrm{h}=25 \mathrm{mg} / \mathrm{kg}$ sulfadoxine and $1.25 \mathrm{mg} / \mathrm{kg}$ pyrimethamine as a single dose plus.

$\mathrm{i}=$ placebo once daily for 3 days.

$\mathrm{j}=10 \mathrm{mg} / \mathrm{kg}$ for once daily for 3 days.

$\mathrm{k}=$ administered as half a tablet ( $20 \mathrm{mg}$ of artemether and $120 \mathrm{mg}$ of lumefantrine) per $5 \mathrm{~kg}$ of body weight in a 6-dose.

$\mathrm{I}=$ single dose of $45 \mathrm{mg}$ of primaquine base.

$\mathrm{m}=500 \mathrm{mg}$ of sulfadiazine every 6 hours for 5 days and $50 \mathrm{mg}$ of pyrimethamine daily for 3 days.

$\mathrm{n}=$ Pyrimethamine $50 \mathrm{mg}$ daily for 3 days.

*two parallel studies involving autologous plasma and control serum.

**the study year is not mentioned in the article.

***two parallel studies involving two strains of $P$. falciparum. Ref. $=$ References.

\section{Study quality assessment}

A summary of the risk of bias assessment of the controlled trials can be found in Table 2. The extent of risk of bias varied across the studies. In general, trials done using artemisinin derivatives had a low risk of bias in most areas, whereas the trials on primaquine had an unclear risk of bias in most areas.

\section{Heterogeneity assessment}

Heterogeneity among the selected published studies was examined and the outcomes are presented in Table 3. A moderate to substantial heterogeneity was observed in the trials used for the two meta-analyses (with artesunate $v s$. without artesunate, primaquine $v s$. other antimalarials). The pooled ORs were calculated by the random-effects model, which assumes that the estimated effect size in different trials follow some distribution [21].

\section{Artesunate-based combinations versus antimalarials without artesunate}

The transmission blocking property of artesunate in combination with other antimalarials (chloroquine, sulfadoxine- pyrimethamine alone, sulfadoxine-pyrimethamine with amodiaquine or with placebo) were compared with the respective standard treatments (controls) without artesunate. The total number of mosquitoes checked for oocyst were 4,013 in the artesunate group and 6,075 in the control group. The OR was 0.36 (95\% CI, 0.14-0.90), which favours artesunate-based combination therapy in reducing the transmission of $P$. falciparum parasite from patients to mosquitoes (Figure 2).

\section{Artemether-lumefantrine versus other antimalarials}

The association between the use of artemetherlumefantrine and the reduction of malaria transmission was investigated. The total number of mosquitoes evaluated for oocyst was 1,695 in artemether-lumefantrine group and 1,845 in control group. The OR was 0.49 (95\% CI, 0.31-0.79), which favours artemether-lumefantrine therapy in reducing the transmission of malaria from patients to mosquitoes (Figure 3).

The meta-analysis was in favour of artemisinin derivatives in reducing malaria transmission (Figures 2 and 3). In two randomised trials, the transmission blocking 
Table 2 Risk of bias assessment within the trials

\begin{tabular}{|c|c|c|c|c|c|c|c|c|}
\hline $\begin{array}{l}\text { Study } \\
\text { location } \\
\text { (year) }\end{array}$ & $\begin{array}{c}\text { Random sequence } \\
\text { generation } \\
\text { (selection bias) }\end{array}$ & $\begin{array}{c}\text { Allocation } \\
\text { concealment } \\
\text { (selection bias) }\end{array}$ & $\begin{array}{c}\text { Blinding of } \\
\text { participants \& } \\
\text { personnel } \\
\text { (performance bias) }\end{array}$ & $\begin{array}{c}\text { Blinding of } \\
\text { outcome } \\
\text { assessment } \\
\text { (detection bias) }\end{array}$ & $\begin{array}{l}\text { Incomplete } \\
\text { outcome data } \\
\text { (attrition bias) }\end{array}$ & $\begin{array}{l}\text { Selective reporting } \\
\text { (reporting bias) }\end{array}$ & Other & Ref. \\
\hline Gambia (2000) & low & low & low & low & low & low & unclear & {$[15]$} \\
\hline Gambia (1999) & low & unclear & low & low & low & low & unclear & {$[16]$} \\
\hline Gambia (1998) & low & unclear & low & low & low & low & unclear & {$[16]$} \\
\hline Kenya (2003-4) & low & unclear & low & low & low & low & unclear & {$[17]$} \\
\hline Gambia (2002) & low & low & low & low & low & low & unclear & [18] \\
\hline USA* & high & high & low & low & unclear & unclear & unclear & [19] \\
\hline USA (1968) & high & high & low & low & unclear & unclear & unclear & {$[20]$} \\
\hline
\end{tabular}

activity of ACTs were compared. In the first study, treatment with artemether-lumefantrine was associated with a lower proportion of infected mosquitoes as compared with dihyroartemisinin-piperaquine (OR 0.53; 95\% CI, 0.37- 0.77) [22]. The second study comparing artemether-lumefantrine and artesunate in combination with sulfadoxine-pyrimethamine did not show any difference in the proportion of infected mosquitoes (OR 1.60; 95\% CI, 0.87-2.98) [17].

\section{Primaquine single dose versus other antimalarials}

The association between single-dose primaquine (45 mg) and malaria transmission blocking from patients to mosquitoes was assessed. Overall, 65 mosquitoes in the primaquine group and 138 mosquitoes in the comparative group were used. The OR was 0.09 (95\% CI, 0.01-0.73), which favours single-dose primaquine therapy in reducing the transmission of malaria from patients to mosquitoes (Figure 4).

\section{Single-dose of primaquine and malaria transmission at different points in time}

Single-dose primaquine from $15 \mathrm{mg}$ to $45 \mathrm{mg}$ were given to individuals diagnosed with $P$. falciparum, and the patients were exposed to mosquito bites at different days, i.e. before and after treatment. The data of mosquito infection rate versus time (treatment days) from 16 patients, reported by multiple studies, is presented in Figure 5.

In more than $93 \%$ of all the patients, the Plasmodium transmission to the mosquitoes had been blocked within the third day of administration of a single dose of primaquine. However, mosquitoes feeding on patients after 10 days of treatment became oocyst-positive. Briefly, this has been revealed in a study that followed patients for two weeks. Mosquitoes, fed on one patient on the 14th day and a second patient on the 11th and 15th days after primaquine treatment, became oocyst-positive (Figure 5).

\section{Addition of primaquine to antimalarials and malaria transmission: the mefloquine case}

Chen and his colleague studied the impact of single-dose mefloquine with and without primaquine $(45 \mathrm{mg}$ ) on the transmission rate of Plasmodium from patients to mosquitoes [26]. Before treatment, the mosquito infection prevalence was similar in mefloquine alone and mefloquine plus primaquine arms. Mosquitoes, fed on membrane feeding apparatus containing blood from patients treated with mefloquine plus primaquine on later days, were not infected unlike the group treated with mefloquine alone that showed a sluggish reduction in infection rate through time (Figure 6).

In the mefloquine plus primaquine group, the transmission of malaria was blocked throughout the duration of follow-up, i.e. 3 weeks (Figure 6). This duration of transmission blockade was longer than the duration (about 10 days) reported in those studies, which used only primaquine (Figure 5).

\section{Discussion}

Preventing mosquitoes from biting by the existing tools (e.g. ITNs and IRS) and blocking the transmission of

Table 3 Statistics to test heterogeneity in the meta-analysis

\begin{tabular}{|c|c|c|c|c|c|}
\hline \multirow[t]{2}{*}{ Comparison } & \multicolumn{4}{|c|}{ Heterogeneity } & \multirow{2}{*}{$\begin{array}{l}\text { Model used for } \\
\text { meta-analysis* }\end{array}$} \\
\hline & $T_{a u^{2}}$ & Q-value & $P_{\text {heterogeneity }}$ & $I^{2}(\%)$ & \\
\hline With artesunate vs. without artesunate & 1.18 & $79.7(\mathrm{df}=5)$ & $<0.01$ & 94 & Random \\
\hline Artemether-lumefantrine vs. other antimalarials & 0.05 & $2.77(\mathrm{df}=2)$ & 0.25 & 28 & Random \\
\hline Primaquine vs. other antimalarial & 1.95 & $5.15(\mathrm{df}=3)$ & 0.16 & 42 & Random \\
\hline
\end{tabular}

*For the reasons mentioned in the method (statistical analysis section), random effects model was chosen for all comparison. 


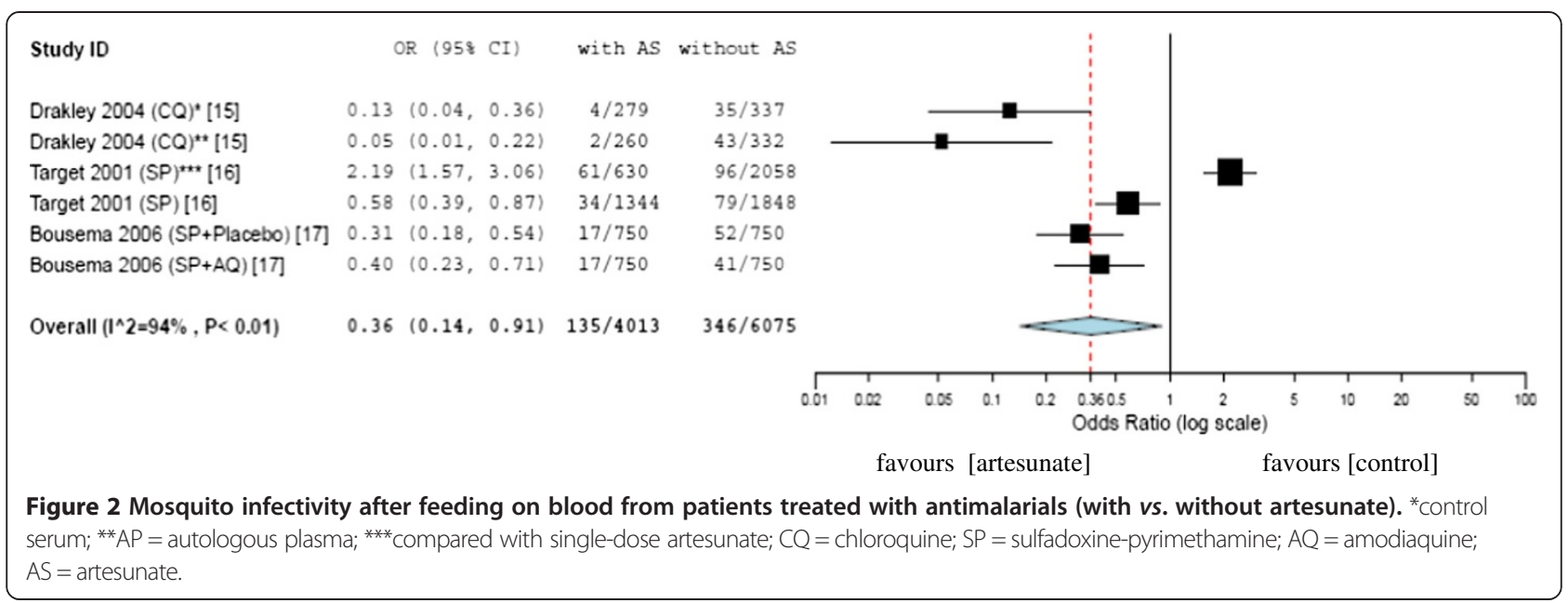

Plasmodium parasites from patients to mosquitoes using agents (vaccine or drugs) may substantially improve public health through reducing the burden of malaria [27]. In areas of stable malaria, a meta-analysis of ITNs on malaria transmission revealed a reduction by $50 \%$ [28]. However, a meta-analysis on existing antimalarials to block the transmission of the parasite from patients to mosquitoes has not yet been done to the author's knowledge.

The current meta-analysis re-affirmed the advantage of ACTs in reducing transmission of Plasmodium to the mosquitoes. In the overall analysis, the odds of transmission of malaria in artesunate-based combination treatment group was 2.78 times less than the odds of transmission of malaria in antimalarials without artesunate (Figure 2). Similarly, the odds of malaria transmission to mosquitoes in artemether-lumefantrine treated group was 2 times less than the odds on other antimalarials used in the studies (Figure 3). Exceptionally, in one trial [16], the odds of parasite transmission was higher in artesunate-based combination therapy than the standard therapy without artesunate. This difference might be attributed to the use of only one dose of artesunate in the trial.
From the current analysis of the published articles, artesunate- and artemether-based therapy could reduce the transmission of the parasite to the mosquitoes. Thus, these medications, in addition to their role in the clinical case management of malaria, can have an impact on the overall transmission rate of malaria and play a role in controlling malaria.

Primaquine, the old antimalarial drug mainly used in terminal cure of $P$. vivax infection, was also tested for its impact on the transmission of Plasmodium to mosquitoes. Trials compared the transmission blocking effect of single-dose primaquine with the conventional antimalarials: sulfadoxine-pyrimethamine and pyrimethamine. The current analysis showed that odds of mosquito infection rate was 11 times less for single-dose primaquine relative to the comparative medicine (Figure 4).

In non-comparative longitudinal trials of single-dose primaquine, the current systematic review presented the trends of mosquito infection rate across successive posttreatment days (Figure 5). There was a rapid drop in mosquito infection rate as illustrated in those mosquitoes feeding on the first and second days post-treatment.

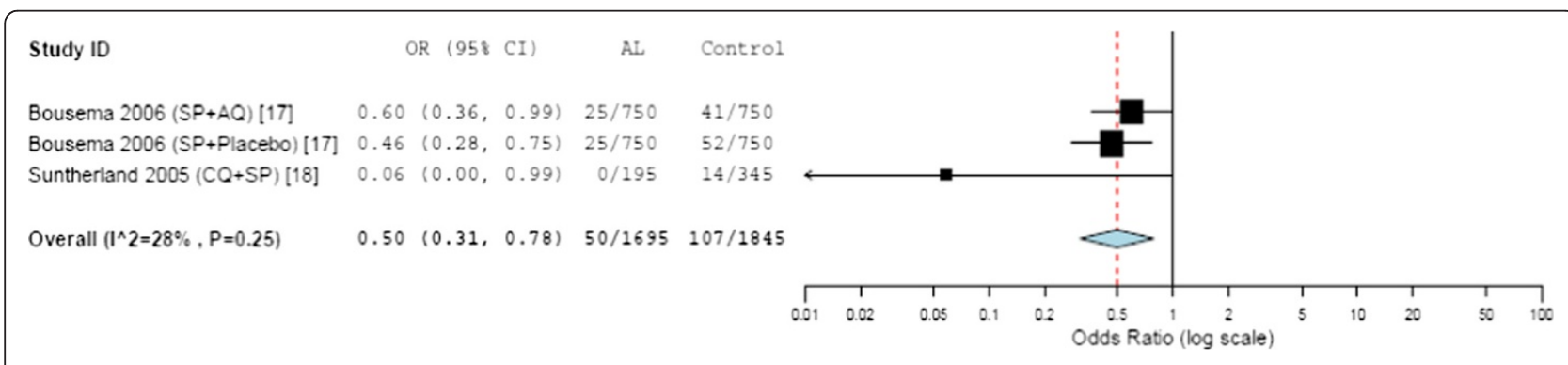

favours [artemether-lumefantrine]

favours [control]

Figure 3 Mosquito infectivity after feeding on blood from patients treated with artemether-lumefantrine versus control (standard therapy). $\mathrm{CQ}=$ chloroquine; $\mathrm{SP}=$ sulfadoxine-pyrimethamine; $\mathrm{AQ}=$ amodiaquine; $\mathrm{AL}=$ artemether-lumefantrine. 


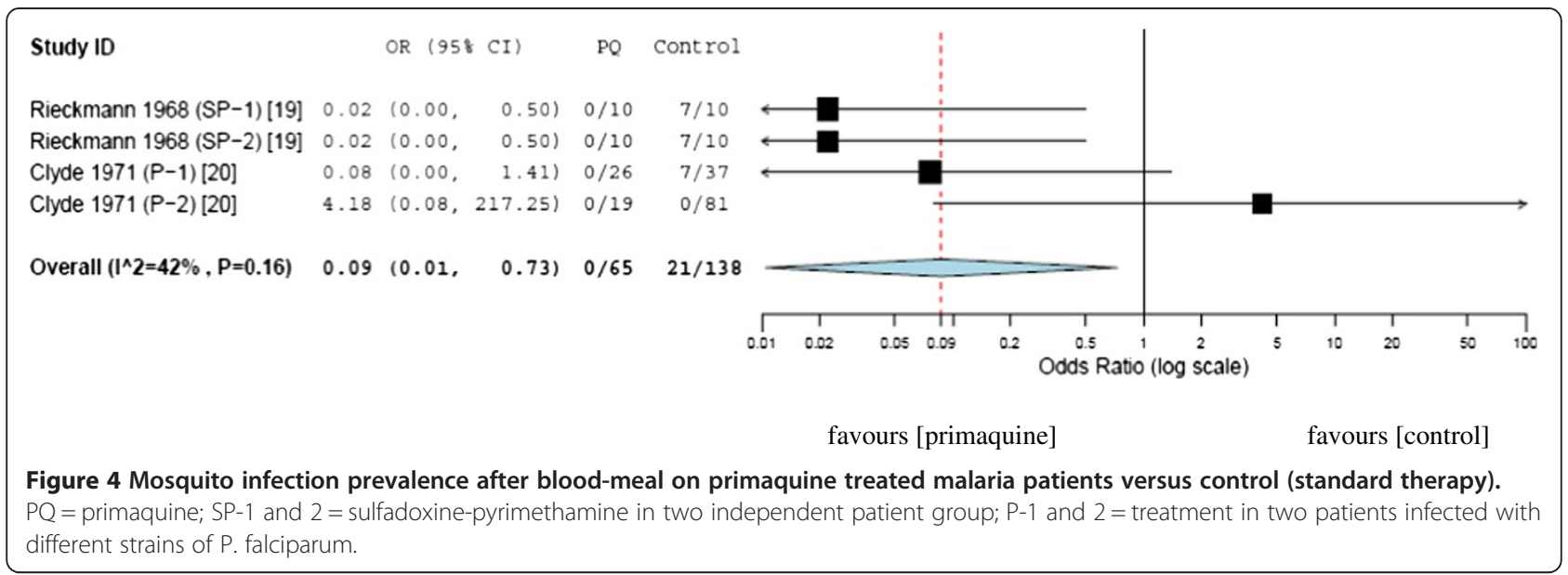

However, the effect was maintained only for a short period as evidenced by the positivity of mosquitoes biting on some patients after the 10 days of single-dose primaquine therapy. As the trials employed single-dose primaquine therapy, which might target only the mature gametocyte [9], the continuity of transmission blockade by a single dose of primaquine fails against the new wave of mature gametocytes that appear after primaquine has been washed out [29].

The use of single-dose primaquine blocks the transmission of malaria temporarily (Figure 5). However, combining it with effective antimalarials - like mefloquine used in the trial conducted by Chen and his colleague - results in a disruption of Plasmodium transmission to the vector for a longer period (Figure 6). This might be explained by the fact that the effective schizonticide (mefloquine), by clearing the parasite, dries out the potential source for a new wave of gametocytes.

Following the introduction of ACTs in malaria case management, many researchers report the additional benefit of ACTs on the partial gametocytocidal effect compared with the non-ACTs regimens [30-34]. Recently, there is also interest of combining ACTs with single-dose primaquine, particularly in areas with a resistant Plasmodium to ACTs or in the phase of malaria elimination. The addition of primaquine to ACTs results in a further reduction in gametocyte carriage rate that can have implications on the extent of malaria transmission [35-39]. However, the optimal time of administration, treatment duration and dose of primaquine needs to be understood for improved outcomes. Further studies are also required to

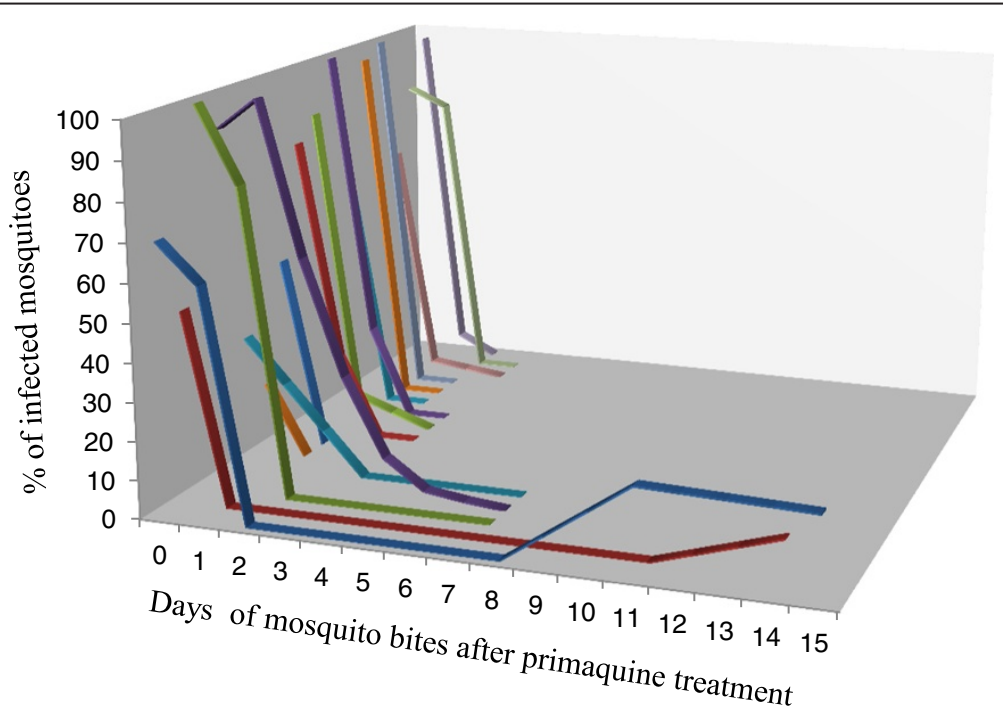

Figure 5 Plasmodium infectivity rate to mosquitoes that fed on falciparum malaria patients treated with a single dose of primaquine. Day zero refers to the percent of oocyst positive mosquito fed on patients before the treatment. Sixteen of each line represents the oocyst positivity of mosquitoes feeding on single patients immediately before treatment and afterwards. Mosquitoes fed on two patients after 10 days of treatment were oocyst positive [19,20,23-25]. 


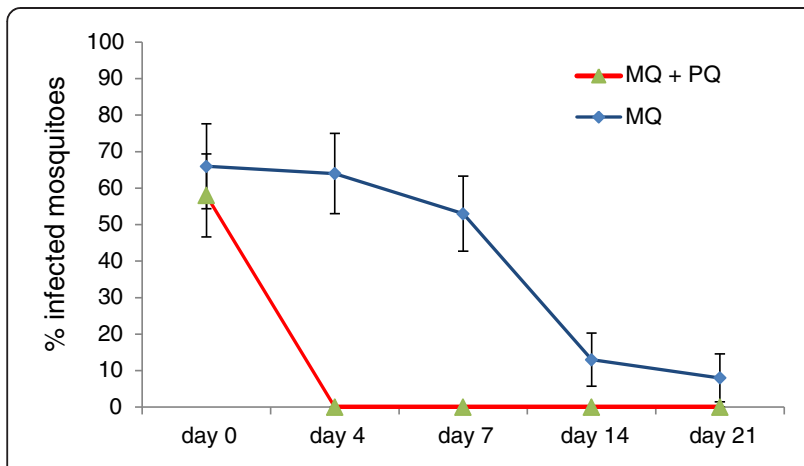

Figure 6 Plasmodium infective rate to mosquitoes after patients treated with mefloquine alone versus mefloquine plus primaquine. The mosquitoes fed via membrane feeding on blood of patients treated with a single dose of mefloquine $(750 \mathrm{mg})$ or a combination with primaquine single dose $(45 \mathrm{mg}) . \mathrm{MQ}=$ mefloquine; $\mathrm{PQ}=$ primaquine [26].

understand the transmission blocking effect upon the addition of primaquine to $\mathrm{ACT}$ regimens at the mosquito level, which is a gold standard approach to evaluate malaria transmission.

The present paper analysed the transmission blocking activity of artemisinin derivatives and primaquine. The clinical trials of artemisinin derivatives and primaquine focused on An. gambiae and An. stephensi; respectively. None of the identified literatures pertained to other dominant malaria vectors such as An. funestus and $A n$. arabiensis [40-42]. In all of the trials included for metaanalysis, similar colonies of mosquitoes in both intervention and control groups were used. By so doing, confounding bias related to the variable infection success in the different species of vectors could be avoided. Of course, if the variability in susceptibility of the vectors to $P$. falciparum infection modified the transmission blocking activity of drugs, trials with different species of malaria vectors having a range of infection success would be required; then systematic reviews should consider subgroup analysis.

Like any retrospective study, this systematic review has a number of limitations. The literature search might have missed some trials. The author assumed that missing reports is unlikely for two reasons. Firstly, a proper search strategy was followed to identify literatures. Secondly, the research groups working on transmission blocking trials at the level of mosquitoes are few. Another concern is the comparison of the reference drugs (artemisinin derivatives and primaquine) with a heterogeneous array of antimalarials probably with different gametocytocidal activity, which in turn might obscure some systematic differences between drugs. To minimize these risk, random analytic method was followed in all data analysis, including in those with little heterogeneity.

\section{Conclusions}

Based on the data reviewed, artemisinin derivatives (artesunate and artemether) and primaquine reduce the transmission of $P$. falciparum from the patient to the mosquitoes. Combining the two medications, after a proper optimization study, might further reduce the transmission of malaria.

\section{Additional files}

Additional file 1: Checklist S1 PRISMA 2009 checklist.

Additional file 2: Table S1. Search strategies for the databases.

\section{Competing interests}

The author declares that he has no competing interests.

\section{Author contribution}

SMA conceived the idea and designed the study, made both qualitative and quantitative synthesis of reported trials, wrote and revised the manuscript.

\section{Acknowledgement}

The author thanks Giancarlo Nardini, a librarian at University of Camerino, for the provision of essential articles. The author is also very grateful to anonymous reviewers for their meticulous reading of the paper.

Received: 5 June 2013 Accepted: 20 September 2013

Published: 24 September 2013

\section{References}

1. World Health Organization: Global Health Observatory. http://www.who.int/ gho/malaria/en.

2. World Health Organization: Malaria-factsheet on the world malaria report 2012. http://www.who.int/malaria/media/world_malaria_report_2012_facts/en/.

3. Murray CJL, Rosenfeld LC, Lim SS, Andrews KG, Foreman KJ, Haring D, Fullman N, Naghavi M, Lozano R, Lopez AD: Global malaria mortality between 1980 and 2010: a systematic analysis. Lancet 2012, 379:413-31.

4. World Health Organization: Media center- World malaria day. http://www. who.int/mediacentre/news/releases/2012/malaria_20120424/en/.

5. Price RN, Nosten F, Luxemburger $C$, ter Kuile FO, Paiphun L, Chongsuphajaisiddhi T, White NJ: Effects of artemisinin derivatives on malaria transmissibility. Lancet 1996, 347:1654-8.

6. World Health Organization: WHO Policy Brief for the Implementation of Intermittent Preventive Treatment of Malaria in Pregnancy using SulfadoxinePyrimethamine (IPTP-SP). http://www.who.int/malaria/publications/atoz/ Policy_brief_IPTp-SP_implementation_11april2013.pdf.pdf.

7. Okumu FO, Moore SJ: Combining indoor residual spraying and insecticidetreated nets for malaria control in Africa: a review of possible outcomes and an outline of suggestions for the future. Malar J 2011, 10:208.

8. Centers for Disease Control and Prevention: Malaria: Current and Future Research. http://www.cdc.gov/malaria/tools_for_tomorrow/research_areas.html.

9. Wilairatana P, Krudsood S, Tangpukdee N: Appropriate time for primaquine treatment to reduce Plasmodium falciparum transmission in hypoendemic areas. Korean J Parasitol 2010, 48:179-182.

10. Okell LC, Drakeley CJ, Ghani AC, Bousema T, Sutherland CJ: Reduction of transmission from malaria patients by artemisinin combination therapies: a pooled analysis of six randomized trials. Malar J 2008, 7:125

11. Moher D, Liberati A, Tetzlaff J, Altman DG, The PRISMA Group: Preferred reporting items for systematic reviews and meta-analyses: The PRISMA Statement. PLoS Med 2009, 6:e1000097.

12. Higgins JPT, Green S: Cochrane Handbook for Systematic Reviews of Interventions Version 5.1.0. www.cochrane-handbook.org.

13. Wallace BC, Schmid CH, Lau J, Trikalinos TA: Meta-Analyst: software for meta-analysis of binary, continuous and diagnostic data. BMC Med Res Methodol 2009, 9:80.

14. DerSimonian R, Laird N: Meta-analysis in clinical trials. Control Clin Trials 1986, 7:177-188. 
15. Drakeley CJ, Jawara M, Targett GAT, Walraven G, Obisike U, Coleman R, Pinder M, Sutherland CJ: Addition of artesunate to chloroquine for treatment of Plasmodium falciparum malaria in Gambian children causes a significant but short-lived reduction in infectiousness for mosquitoes. Trop Med Int Health 2004, 9:53-61.

16. Targett G, Drakeley C, Jawara M, Seiden L, Coleman R, Deen J, Pinder M, Doherty T, Sutherland C, Walraven G, Milligan P: Artesunate reduces but does not prevent posttreatment transmission of Plasmodium falciparum to Anopheles gambiae. J Infect Dis 2001, 183:1254-9.

17. Bousema JT, Schneider P, Gouagna LC, Drakeley CJ, Tostmann A, Houben R, Githure JI, Ord R, Sutherland CJ, Omar SA, Sauerwein RW: Moderate effect of artemisinin-based combination therapy on transmission of Plasmodium falciparum. J Infect Dis 2006, 193:1151-9.

18. Sutherland CJ, Ord R, Dunyo S, Jawara M, Drakeley CJ, Alexander N, Coleman R, Pinder M, Walraven G, Targett GAT: Reduction of malaria transmission to Anopheles mosquitoes with a six-dose of regimen o Coartemether. PLoS Med 2005, 2:e92.

19. Rieckmann KH, McNamara JV, Frischer H, Stockert TA, Carson PE, Powell RD Gametocytocidal and sporontocidal effects of primaquine and of sulfadiazine with pyrimethamine in a chloroquine-resistant strain of Plasmodium falciparum. Bull World Health Organ 1968, 38:625-32.

20. Clyde DK, Miller RM, Music SI, McCarthy VC: Prophylactic and sporontocidal treatment of chloroquine-resistant Plasmodium falciparum from Vietnam. Am J Trop Med Hyg 1971, 20:1-5.

21. Schrol JB, Moustgaard R, Gøtzsche PC: Dealing with substantial heterogeneity in Cochrane reviews. Cross-sectional study. BMC Med Res Methodol 2011, 11:22.

22. Sawa P, Shekalaghe SA, Drakeley CJ, Sutherland CJ, Mweresa CK, Baidjoe AY, Manjurano A, Kavishe RA, Beshir KB, Yussuf RU, Omar SA, Hermsen CC, Okell L, Schallig HD, Sauerwein RW, Hallett RL, Bousema T: Malaria transmission after artemether-lumefantrine and dihydroartemisinin-piperaquine: a randomized trial. J Infect Dis 2013, 207:1637-45.

23. Clyde DK, DuPont HI, Miller RM, McCarthy VC: Prophylactic and sporontocidal treatment of chloroquine-resistant Plasmodium falciparum from Malaya. Trans R Soc Trop Med Hyg 1970, 64:834-838.

24. Burgess RW, Bray RS: The Effect of a Single Dose of Primaquine on the Gametocytes, Garnetogony and Sporogony of Laverania falciparum. Bull World Health Organ 1961, 24:451-6.

25. Young MD: The effect of small doses of primaquine upon malaria infections. Indian J Malariol 1959, 13:69-72.

26. Chen PQ, Li GQ, Guo XB, He KR, Fu YX, Fu LC, Song YZ: The infectivity of gametocytes of Plasmodium falciparum from patients treated with artemisinin. Chin Med J 1994, 107:709-11.

27. Griffin JT, Hollingsworth TD, Okell LC, Churcher TS, White M, Hinsley W, Bousema T, Drakeley CJ, Ferguson NM, Basáñez MG, Ghani AC: Reducing Plasmodium falciparum malaria transmission in Africa: a model-based evaluation of intervention strategies. PLoS Med 2010, 7:e1000324.

28. Lengeler $C$ : Insecticide-treated bed nets and curtains for preventing malaria. Cochrane Database Syst Rev 2004, 2, CD000363.

29. Fletcher KA, Evans DAP, Gilies HM, Greaves J, Bunnag D, Harinasuta T: Studies on the pharmacokinetics of primaquine. Bull World Health Organ 1981, 59:407-12.

30. Carmona-Fonseca J, Arango E, Blair S: Gametocytemia in falciparum malaria treated with amodiaquine or artesunate. Biomedica 2008, 28:195-212.

31. Agomo PU, Meremikwu MM, Watila IM, Omalu IJ, Odey FA, Oguche S, Ezeiru VI, Aina OO: Efficacy, safety and tolerability of artesunatemefloquine in the treatment of uncomplicated Plasmodium falciparum malaria in four geographic zones of Nigeria. Malar J 2008, 7:172.

32. Zwang J, Olliaro P, Barennes $H$, Bonnet $M$, Brasseur P, Bukirwa $H$, Cohuet $S$, D'Alessandro U, Djimdé A, Karema C, Guthmann JP, Hamour S, Ndiaye JL, Mårtensson A, Rwagacondo C, Sagara I, Same-Ekobo A, Sirima SB, van den Broek I, Yeka A, Taylor WR, Dorsey G, Randrianarivelojosia M: Efficacy of artesunate-amodiaquine for treating uncomplicated falciparum malaria in sub-Saharan Africa: a multi-centre analysis. Malar J 2009, 8:203.

33. Sowunmi A, Nkogho OO, Okuboyejo TM, Gbotosho GO, Happi CT, Adewoye EO: Effects of mefloquine and artesunate mefloquine on the emergence, clearance and sex ratio of Plasmodium falciparum gametocytes in malarious children. Malar J 2009, 8:297.

34. Osorio L, Gonzalez I, Olliaro P, Taylor WR: Artemisinin-based combination therapy for uncomplicated Plasmodium falciparum malaria in Colombia. Malar J 2007, 6:25.
35. Pukrittayakamee S, Chotivanich K, Chantra A, Clemens R, Looareesuwan S, White NJ: Activities of artesunate primaquine against asexual and sexual stages parasites in falciparum malaria. Antimicrob Agents Chemother 2004, 48:1329-34

36. Smithuis F, Kyaw MK, Phe O, Win T, Aung PP, Oo AP, Naing AL, Nyo MY, Myint NZ, Imwong M, Ashley E, Lee SJ, White NJ: Effectiveness of five artemisinin combination regimens with or without primaquine in uncomplicated falciparum malaria: an open-label randomised trial. Lancet Infect Dis 2010, 10:673-81.

37. Eliana M, Yulieth A, Carmona-Fonseca J: Efficacy of different primaquinebased antimalarial regimens against Plasmodium falciparum gametocytemia. Acta Trop 2012, 122:177-82.

38. Sutanto I, Suprijanto S, Kosasih A, Dahlan MS, Syafruddin D, Kusriastuti R, Hawley WA, Lobo NF, Ter Kuile FO: The effect of primaquine on gametocyte development and clearance in the treatment of uncomplicated falciparum malaria with dihydroartemisinin-piperaquine in South Sumatra, Western Indonesia: an open-label, randomized, controlled trial. Clin Infect Dis 2013, 56:685-93.

39. Shah NK, Schapira A, Juliano JJ, Srivastava B, Macdonald PD, Poole C, Anvikar A, Meshnick SR, Valecha N, Mishra N: A non-randomized controlled trial of artesunate plus sulfadoxine-pyrimethamine with or without primaquine for preventing the post-treatment circulation of Plasmodium falciparum gametocytes. Antimicrob Agents Chemother 2013, 57:2948-54.

40. Mwangangi JM, Muturi EJ, Muriu SM, Nzovu J, Midega JT, Mbogo C: The role of Anopheles arabiensis and Anopheles coustani in indoor and outdoor malaria transmission in Taveta District, Kenya. Parasit Vectors 2013, 6:114.

41. Lwetoijera DW, Kiware SS, Mageni ZD, Dongus S, Harris C, Devine GJ, Majambere S: A need for better housing to further reduce indoor malaria transmission in areas with high bed net coverage. Parasit Vectors 2013, 6:57.

42. Tchouassi DP, Quakyi IA, Addison EA, Bosompem KM, Wilson MD, Appawu MA, Brown CA, Boakye DA: Characterization of malaria transmission by vector populations for improved interventions during the dry season in the Kpone-on-Sea area of coastal Ghana. Parasit Vectors 2012, 5:212.

doi:10.1186/1756-3305-6-278

Cite this article as: Abay: Blocking malaria transmission to Anopheles mosquitoes using artemisinin derivatives and primaquine: a systematic review and meta-analysis. Parasites \& Vectors 2013 6:278.

\section{Submit your next manuscript to BioMed Central and take full advantage of:}

- Convenient online submission

- Thorough peer review

- No space constraints or color figure charges

- Immediate publication on acceptance

- Inclusion in PubMed, CAS, Scopus and Google Scholar

- Research which is freely available for redistribution 